\title{
Design of Universal Filter using MO-CCCDTA on 32nm FinFET Technology
}

\author{
Shantanu Chakraborty \\ Student of BE, \\ Department of ECE, \\ Birla Institute of Technology, \\ Mesra,Jaipur Campus.
}

\begin{abstract}
The paper aims at designing a universal filter using current mode circuit. The main advantages of current mode circuits over voltage mode circuits are better linearity in performance,higher bandwidth responses, low noise performances. The preferred technology is $32 \mathrm{~nm}$ FinFET technology since CMOS technology shows short channel effects and DIBL (Drain Induced Bareer Lowering) which hampers the performance of the circuit. As channel length reduces from $45 \mathrm{~nm}$ CMOS technology to $32 \mathrm{~nm}$ technology, the FinFET technology shows superior performances. The paper shows all the responses ( Low Pass, High Pass,Band Pass and Band Reject) of the Universal Filter. Bias currents are applied to reduce the effects of parasitic capacitances and resistances in the circuit. The circuit uses the MO-CCCDTA as the building block of the filter.The simulation is done on HSPICE software.
\end{abstract}

\section{General Terms}

Current Mode Circuit, Parasitic capacitances,Universal Filter.

\section{Keywords}

Bandwidth, FinFET,HSPICE,MO-CCCDTA(modified output current controlled current differencing transconductance amplifier),short channel effects.

\section{INTRODUCTION}

In the last decade, there has been much effort to reducethe supply voltage of electronic circuits. This is due to the command for portable and battery-powered equipment[1].Since a low-voltage operating circuit becomes necessary, the current-mode technique is ideally suited for this purposemore than the voltage-mode one[5]. Consequently, there is agrowing interest in synthesizing the current-mode circuits because of more their potential advantages such as larger dynamic range, higher signal bandwidth, greater linearity,simpler circuitry and low power consumption[8].

\section{About the CDTA and CCCDTA :}

The CDTA is a two input device that takes two current inputs at two terminals namely Ip and In and produces the output which is a difference of the input currents. It consists of :

1. The linear differencing circuit

2. The transconductance stage

3. The amplifier at the output

The modified version of CDTA - The CCCDTA implements the basic CDTA circuit where the output is controlled by current sources.[6]
CCCDTA properties are similar to that of CDTA except that input voltages are not zero and it has finite resistances $\mathrm{Rp}$ and $\mathrm{Rn}$ at $\mathrm{p}$ and $\mathrm{n}$ input terminals.

These resistances are equal and can be controlled by bias currents.

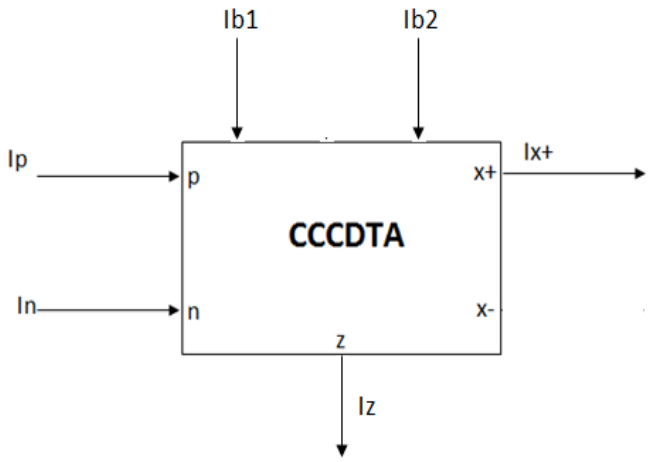

Fig 1. Block Diagram of CCCDTA

CDTA cannot be controlled the parasitic resistances at two current input ports so when it used in some circuits, it must unavoidably require some external passive components. This makes it not appropriate for IC implementation due to occupying more chip area.[3]The purpose of this paper is to design and synthesize a modified-version CDTA, which is newly named current controlled current differencing transconductance amplifier (CCCDTA) and using a CMOS technology.[2] The parasitic resistances at two current input ports can be controlled by an input bias current, then it does not need a resistor in practical applications.

\section{INTRODUCTION TO FinFET TECHNOLOGY}

As more channel length is shortened, the Gate loses control over the flow of careers from source to drain and the device prematurely turns ON. There is almost zero turn off due to the reduced effect of Gate voltage over the careers. This leads to subthreshold leakage when potential is less than the threshold voltage.[7]Thus, in FinFET, we introduce a thin oxide layer between the source and drain and to which we fabricate atleast two gates .[9] Thus, instead of one gate controlling the flow of careers, both the gates maintain the potential across the source and drain and thus channel length depends entirely on the length and thickness of the Fin. FinFETs possess the following key advantages over bulk MOSFETs: reduced leakage,excellent subthreshold slope, and better voltage gain without degradation of noise or linearity[7]. 


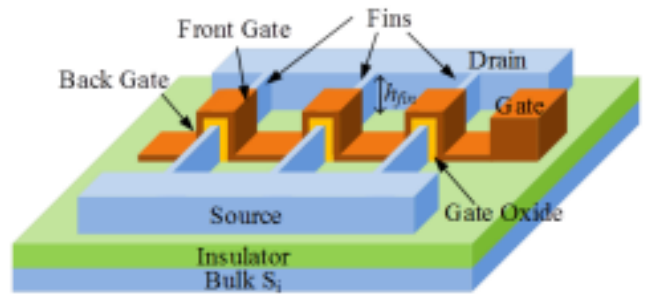

Fig 2.FinFET Structure

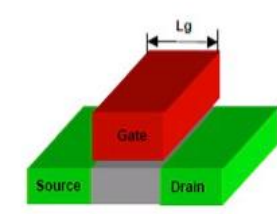

Conventional Planar FET

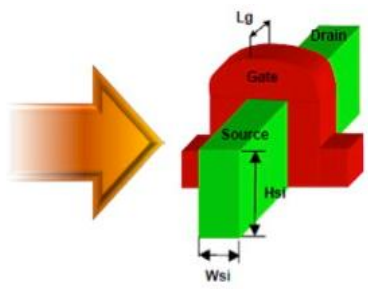

Fig 3.Moving from CMOS to FinFET

\section{THE UNIVERSAL FILTER}

The main application of the proposed CCCDTA is a current mode biquad filter. It employs only one active element and two grounded capacitors, which is easy to fabricate, differing from the previous models.

The modified version of the CCCDTA to the multiple output is used where currents are in opposite directions. Capacitors are used for high pass and band pass applications.[4]

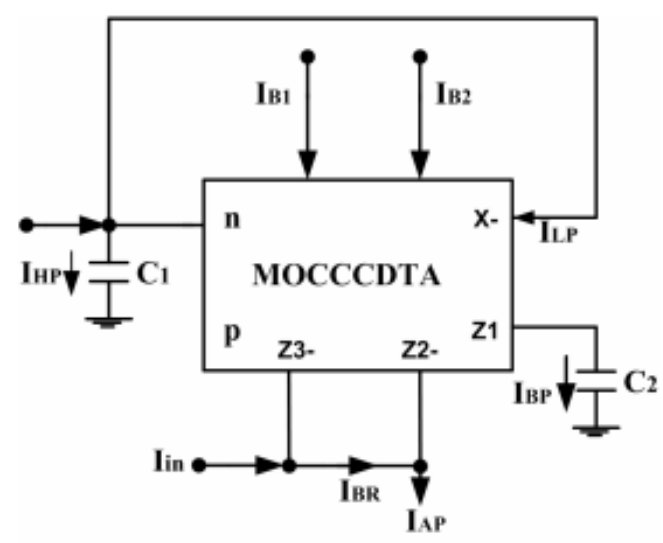

Fig 4. The universal Filter Block Diagram

The circuit implementation consists of mixed translinear loops (M1,M6).[6] The mixed loops are DC biased by IB1 using current mirrors (M7M10) and (M14M16).The output z1 terminal that generates the current difference of $p$ and $n$ terminals is realized using transistors(M11M13 and M17M21).[10]M22 and M23 function as a differential amplifier to convert an input voltage to an output current. M24 and M25 work as a simple current mirror.[4].

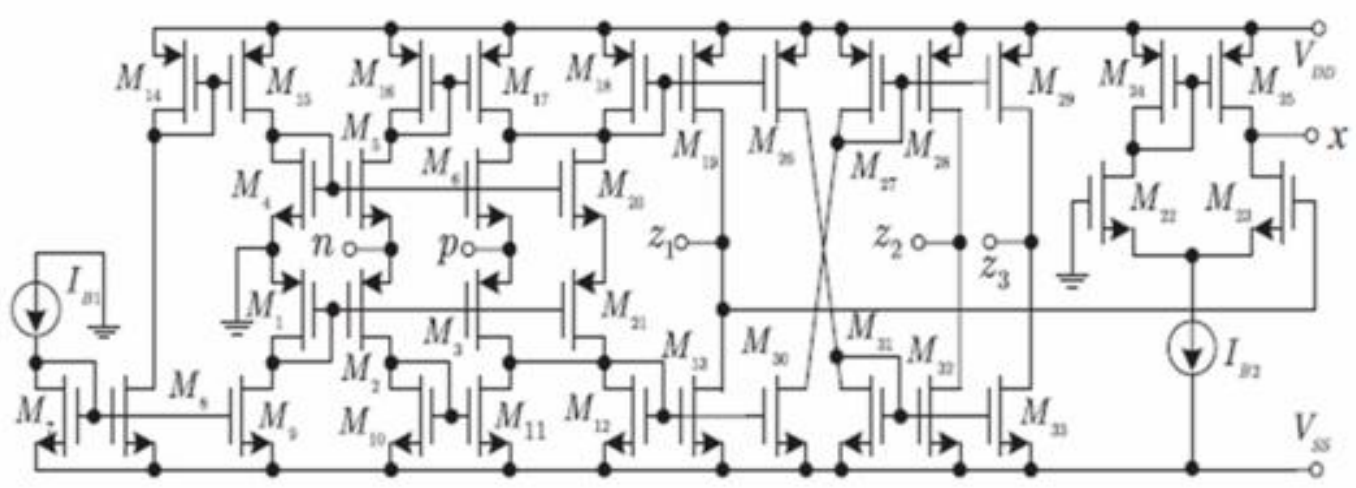

Fig 5. Internal Circuit Diagram Of the CCCDTA

\section{RESULTS AND DISCUSSIONS}

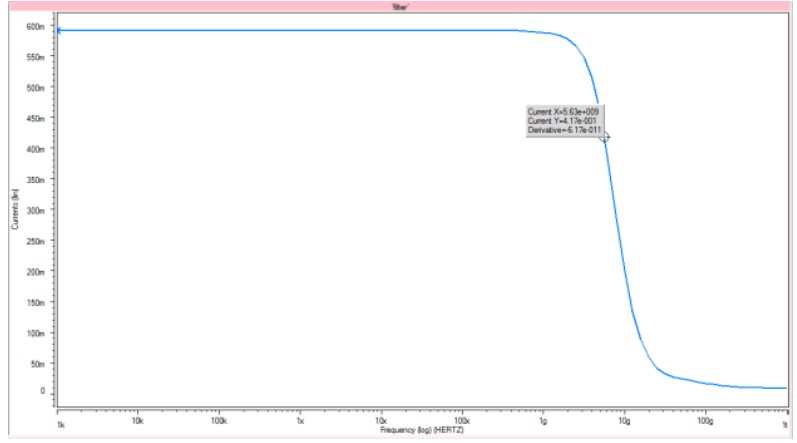

Fig 6. Low Pass Response - 3dB frequency-5.63GHz

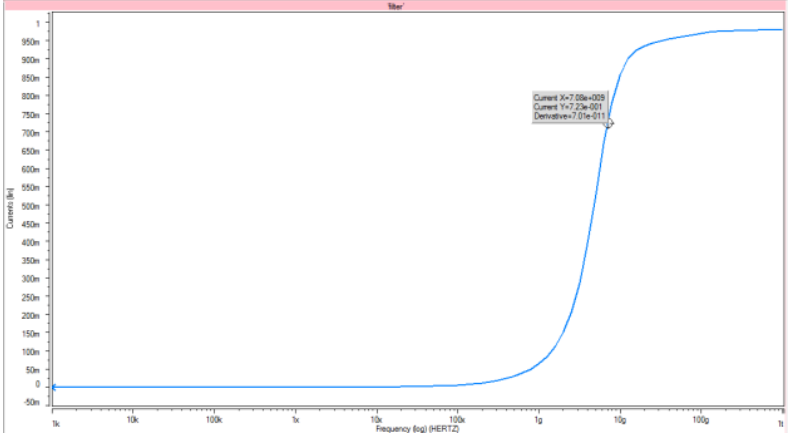

Fig 7 . High Pass Response - 3dB frequency-7.08GHz 


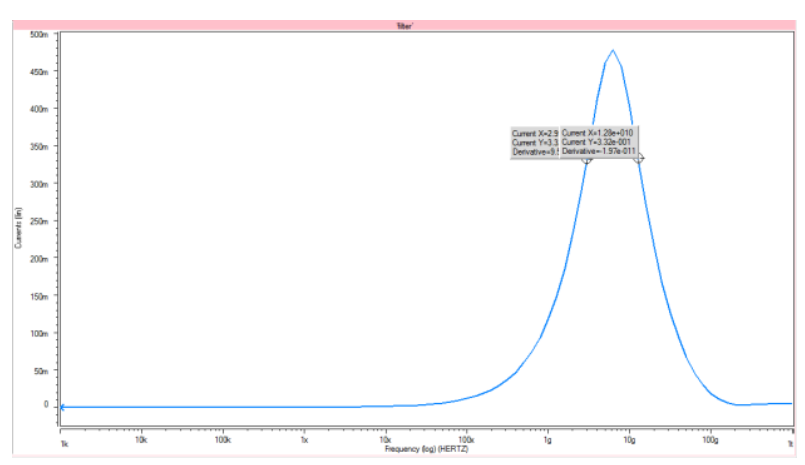

Fig 8. . Band Pass Response - BW-9.81GHz

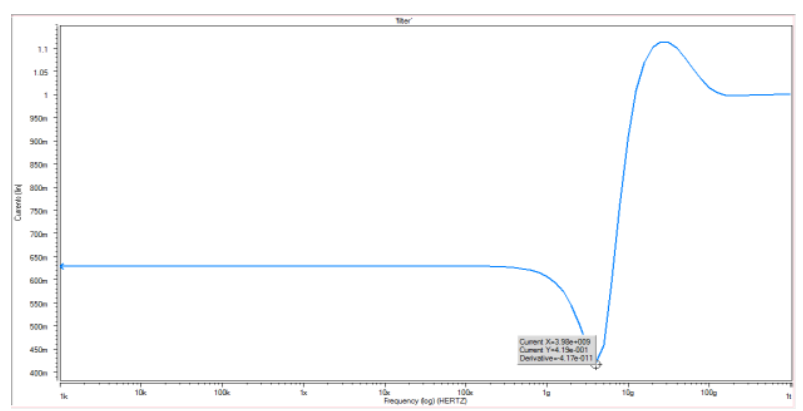

Fig 9. Band Reject Response - Notch frequency-3.98GHz
Table 1.FinFET Parameters for simulation.

\begin{tabular}{|l|l|}
\hline \multicolumn{2}{|c|}{ FINFET PARAMETERS USED } \\
\hline 1. & Length of the drain-gate interface $=32 \mathrm{~nm}$ \\
\hline 2. & Width of the drain-gate interface $=80 \mathrm{~nm}$ \\
\hline 3. & Thickness of oxide $=1.4 \mathrm{~nm}$ \\
\hline 4. & Thickness of buried oxide $=1.4 \mathrm{~nm}$ \\
\hline 5. & Threshold voltage $=0.0259 \mathrm{~V}$ \\
\hline 6. & Power supplies (Vdd and $\mathrm{Vss})=0.5 \mathrm{~V}$ \\
\hline
\end{tabular}

Table2. Comparison with Previous Works

\begin{tabular}{|l|l|l|l|l|l|}
\hline Ref. & Technology & Active Element & Passive Elements & Bias Currents & Bandwidth \\
\hline$[2]$ & $250 \mathrm{~nm}$ & CCDDCCTA & $\begin{array}{l}\mathrm{C} 1=\mathrm{C} 2=100 \mathrm{pF} \\
\mathrm{R} 1=\mathrm{R} 2=1 \mathrm{~K} \Omega\end{array}$ & $\mathrm{Ib} 1=25 \mu \mathrm{A} ; \mathrm{Ib} 2=200 \mu \mathrm{A}$ & $1.28 \mathrm{MHz}$ \\
\hline$[1]$ & $350 \mathrm{~nm}$ & $\mathrm{CDTA}$ & $\begin{array}{l}\mathrm{C} 1=\mathrm{C} 2=1 \mathrm{nF} ; \\
\mathrm{R} 1=\mathrm{R} 2=1 \mathrm{~K} \Omega\end{array}$ & $\mathrm{Ib} 1=\mathrm{Ib} 2=100 \mu \mathrm{A}$ & $130 \mathrm{KHz}$ \\
\hline$[3]$ & $180 \mathrm{~nm}$ & VDTA & $\begin{array}{l}\mathrm{C} 1=\mathrm{C} 2=0.01 \mathrm{nF} \\
\mathrm{R}=1.58 \mathrm{~K} \Omega\end{array}$ & $\mathrm{Ib} 1=150 \mu \mathrm{A} ; \mathrm{Ib} 2=42.38 \mu \mathrm{A}$ & $1 \mathrm{MHz}$ \\
\hline$[4]$ & $350 \mathrm{~nm}$ & CCCTA & $\mathrm{C} 1=\mathrm{C} 2=7.5 \mathrm{pF}$ & $\mathrm{Ib} 1=\mathrm{Ib} 2=7.5 \mu \mathrm{A}$ & $1.8 \mathrm{MHz}$ \\
\hline$[6]$ & $360 \mathrm{~nm}$ & CCCDTA & $\begin{array}{l}\mathrm{C} 1=\mathrm{C} 2=0.16 \mathrm{nF} \\
\mathrm{Rp}=\mathrm{Rn}=821- \\
25.1 \mathrm{~K} \Omega\end{array}$ & $\mathrm{Ib} 1=\mathrm{Ib} 2=50 \mu \mathrm{A}$ & $282 \mathrm{MHz}$ \\
\hline $\begin{array}{l}\text { This } \\
\text { Work }\end{array}$ & $32 \mathrm{~nm}$ & CCCDTA & $\mathrm{C} 1=\mathrm{C} 2=3 \mathrm{~F}$ & $\mathrm{Ib} 1=20 \mu \mathrm{A} ; \mathrm{Ib} 2=10 \mu \mathrm{A}$ & $9.81 \mathrm{GHz}$ \\
\hline
\end{tabular}

\section{REFERENCES}

[1] Anisur Rehman Nasir and S.N.Ahmad. "Single CDTA based current- mode universal filter with grounded capacitors." International Journal Of Electronics Engineering, 4:73-75, 2012.

[2] Ajay Kumar Kushwala and Sajal K.Paul. "Current mode universal filter using single CCDDCCTA." Journal of Circuits and Systems, 6:224-236, 2015

[3] Dinesh Prasad, Data Ram Bhaskar, and Mayank Srivastava. "Universal current mode biquad filter using a VDTA". Journal of Circuits and Systems., 4:29-33, 2013.
[4] Sajai Vir Singh, Sudhanshu Maheshwari, and Durg Singh Chauhan. "Single MO-CCCCTA based electronically tunable current transimpedence mode biquad universal filter.'Journal of Circuits and Systems, 2:1-6, 2011.

[5] Raj Senani, Kasim Karam Abdalla, and Data Ram Bhaskar. "A state variable method for realisation of universal current mode biquads." Journal of Circuits and Systems, 2:286-292, 2011.

[6] "Montree Siripruchyanun and Wanai Jaikla. CMOS current controlled current differencing transconductance amplifier and applications to analog signal processing." International Journal of Electronics and Communications(AEU), 62:277-287, 2007. 
[7] Mayur Bhole,Aditya Kurude,Sagar Pawar."FinfetsBenefits,Drawbacks and Challenges".International Journal Of Engineering Sciences and Research Technology.2:November 2013.

[8] P.E. Allen and D.R. Holberg. CMOS analog circuit design. New York: Oxford University Press, 2002.
[9] Ahmed Yahya Morsy. "A voltage-mode circuit structure using FinFet Transconductance Topology".International Journal of Modern Trends in Engineering and Research.390,2015.

[10] Lattenberg and Vrba. Filters with current amplifiers for high-speed communication. International Conference on Systems and Mobile Communications and Learning Technologies, 150, No. 150:23-29, Apr. 2006. 